\title{
Enhancing frequency stability by integrating non-conventional power sources through multi-terminal HVDC grid
}

\author{
4 \\ Ayman B. Attya ${ }^{\mathrm{b}}$, José Luis Domínguez-García ${ }^{\mathrm{a}}$, F.D. Bianchi ${ }^{\mathrm{a}}$, Olimpo \\ Anaya-Larab \\ ${ }^{a}$ IREC Catalonia Institute for Energy Research, Jardins de les Dones de Negre 1, $2 a$. \\ 08930 Sant Adrià de Besòs, Barcelona, Spain \\ ${ }^{b}$ Department of Electronic and Electrical Engineering, University of Strathclyde, Glasgow, \\ UK
}

10

The 2050 targets established by the EU will foster both larger penetration of renewable energy, especially wind power, and more cross-border interconnections. Moreover, this new framework requires the non-conventional power sources and power converter-based systems to be responsible for the duties traditionally carried out by conventional synchronous generators as frequency support. This paper presents how different power-electronic based technologies can provide frequency support individually and in a coordinated manner (with different priority given by the deadbands) ensuring a stable operation. The implemented scenarios examine challenging conditions, where the primary reserve of the interconnected conventional, renewable, and storage generation is fully utilized to tackle frequency incidents. This demonstrates how the joint regulation of the power electronic-based technologies enhances the frequency stability of the AC synchronous areas. The different control schemes and their interaction are investigated in Cigré DC grid benchmark adapted for frequency stability studies and implemented in Matlab/Simulink simulation tool. This modified grid includes 5-terminal HVDC grid with two offshore wind farms and three AC networks including battery and onshore wind farms.

11

12

Keywords: wind power, HVDC transmission, multi-terminal HVDC grid, energy storage, frequency support, ancillary services

Email address: jldominguez@irec.cat Corresponding author (José Luis

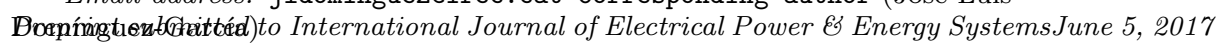




\section{Introduction}

The European Union (EU) has pushed towards the full decarbonization of the energy systems with the targets and plans set for 2050, which aim to reduce the greenhouse gas emission levels of 1990 by $80-95 \%$ [1]. It is expected that this objective will foster the electricity generation share of renewable energy sources up to $100 \%$ [2]. The European Wind Initiative (EWI) foresees that, under this green scenario, wind energy supply about $50 \%$ of Europe electricity needs [3].

To achieve such penetration level, wind power plant installations have to continue increasing. The current trend is to develop larger, in both size and ratings, wind turbines and to install them offshore due to less space restrictions and better wind conditions [4]. In addition, offshore wind farms are moving to farther locations with distances longer than $100 \mathrm{~km}$ from shore [5].

According to these changes, high voltage direct current (HVDC) transmission technology become an attractive option. For long distances and large amount of transmitted power, HVDC is a strong competitor compared to conventional high voltage alternate current (HVAC) [6]. In order to allow larger penetration of offshore wind power (and renewables in general) into the power system, more interconnection and power sharing capability between different countries are required (e.g. SuperGrid concept [7]). Thus, taking advantage of offshore wind power and the HVDC technology, multi-terminal HVDC networks can be integrated to make it real [8]. As an initial step, a HVDC link is planned to connect between Norway and Scotland (i.e. NorthConnect [9]).

The reduction of global inertia is one of the major barriers for power systems that is caused by the increased renewable energy penetration and the shutdown or replacement of conventional synchronous generators (e.g. nuclear) as well as the increment of generation connected through power electronic based systems (i.e. inverter-based, HVDC links, MultiTerminal-HVDC) and the installation of energy storage and FACTS which may help on ensuring stable and secure operation. This leads to a change in power system dynamics making the net- 
work more vulnerable to frequency excursions. In order to mitigate that critical impact and keep the power system stable and secure, transmission system operators (TSOs) are developing novel grid codes with more restrictive and/or novel requirements to the generation (including wind) and power transmission systems (i.e. HVDC) [10-13]. These novel grid codes state that HVDC systems and any type of generation of a certain size (above $50 \mathrm{MW}$ in continental Europe, $10 \mathrm{MW}$ in Great Britain or $5 \mathrm{MW}$ in Ireland) should provide frequency support [11].

Since wind power and HVDC systems are power-electronic-based technologies, they have the capability of fast active power regulation, making them suitable for primary frequency support becoming the first protective barrier to frequency instability. In this regard, wind power may provide such support to the grid by different ways depending on the time-frame objective. On one hand, supporting fast primary response by delivering the kinetic energy naturally stored in the rotating masses within the wind turbine (i.e. inertia response) [14-16]. On the other hand, supporting slow primary response by either maintaining certain power reserves on wind turbines through de-loading or over-speeding control techniques [17-19], or coordinating wind farm response with energy storage systems $[20,21]$. In the HVDC based systems, the transmission network may contribute to frequency support through modifying the power sharing among the different stations [22-24] or by trying to take advantage of the existing energy stored within the capacitors of the DC side, which could act as DC grid inertia [25, 26].

This paper integrates different theoretically-mature frequency support methods from wide range of conventional power sources and non-conventional power electronic based technologies including onshore and offshore wind power, battery energy storage and MT-HVDC. Thus, the interactions between the responses of these controllers are examined and compared. The key contribution is to show the need of potential coordination between different controllers that have the same major objective, because if they act simultaneously it could jeopardize their responses. The available control methods are modified to produce 
a simplified picture of the proposed coordination and its impact on frequency stability. For example, properly tuned deadbands could maintain reasonable coordination and prioritization relying on the profile of each technology (i.e. available power reserve, speed of response, control methods and parameters). The applied case studies have been developed to compare the integration and coordination levels between different generation assets and controllers that are able to provide frequency support. The proposed control methods acknowledge the operation limits of different elements (e.g. BESS state of charge, converter stations capacities, available primary reserve, etc.).

In addition, a supplementary controller is developed to enable the battery energy storage system (BESS) to respond to the abrupt changes in power delivery across the MT-HVDC grid. To improve the credibility of the obtained results different communication delays are applied, as well as severe scenarios (e.g. very steep wind speed drops and low available stored energy) are thoroughly investigated. This paper focuses on frequency stability, the control methods are dedicated to provide and enhance frequency support. The analysis of system response to other types of faults and stability issues is out of scope. However, the holistic control method of the MT-HVDC grid is capable of adapting the requirements of the integrated systems because it is based on consensus theory. As an illustration, if a MT-HVDC converter station suffers a fault or one of the dc lines is lost, the control will modify autonomously the power export/import set-points in all $\mathrm{AC}$ areas and wind farms trying to cope with the new operation conditions of the whole system. The proposed case studies are evaluated through dynamic simulations in a 5-terminal HVDC network based on the Cigré DC grid adapted for frequency stability studies. The model have been developed in Matlab/Simulink simulation tool. The implemented benchmark accommodates two offshore wind farms that are connected to two stations of the MT-HVDC and three synchronous areas. In one AC grid a battery energy storage system is installed; whilst in another AC network an onshore wind farm is integrated. 


\section{Frequency support methods}

In this section, the frequency support methods applied to different nonconventional power sources including both onshore and offshore wind power plants, BESS and MT-HVDC are explained.

\subsection{Wind power plants}

As previously stated, to enable the wind power plants to provide frequency support an increment on active power generation is required. In particular, wind power plants can provide primary frequency support through two main ways, i.e. naturally stored kinetic inertia energy or maintaining certain reserve levels. In this paper, two different wind turbines are integrated offshore and onshore to investigate the interactions between WTGs from different manufacturers

\subsubsection{Onshore wind power plants}

The partial de-loading method is implemented to the onshore wind farm (OWF) [18]. The partial de-loading method integrates two main concepts to enable wind power to provide frequency support, namely, pitch de-loading and kinetic energy extraction. This aims to minimize energy losses that occur due to continuous de-loading. This method applies four operation regions according to the incident WS as illustrated in Figure 1. In this paper, an average WS is examined, hence, each WTG in the onshore WF in Area 2 is operating in region 2 under conventional pitch de-loading. This method does not rely on frequency measurement to manage the amount of provided support power but only as a trigger (i.e. activation-deactivation) signal. However, it requires rough estimate of the incident wind speed to determine operational region and the potential power reserves.

\subsubsection{Offshore wind power clusters (OWPCs)}

A continuous pitch de-loading approach is applied to OWPCs, where the pitch angle is adjusted to keep a certain percentage of the available power as reserve. A droop control is implemented to drive the supportive power surge 


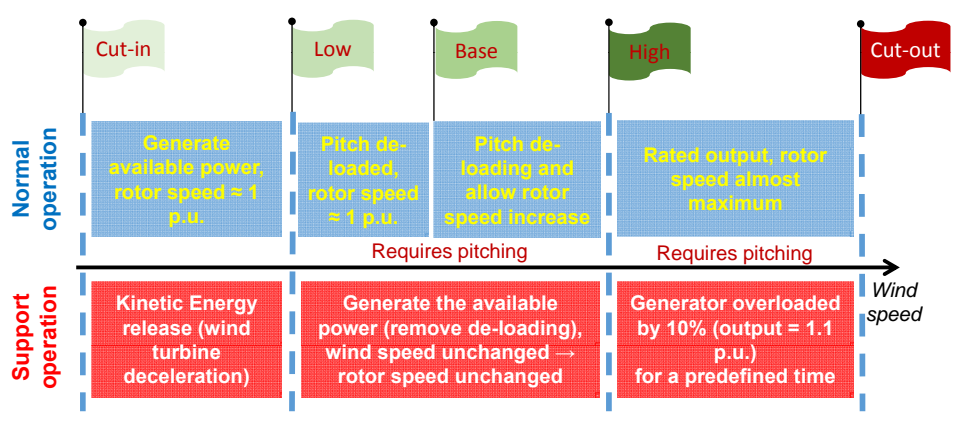

Figure 1: Simplified illustration of the partial de-loading method

such that it is proportional to the frequency deviation, as shown in Figure 2(a). The frequency drop initiates a regulated removal of this de-loaded state until the frequency reaches a certain threshold where the wind turbine is already providing the total amount of available power to the grid, as can be seen in 2(b). The presumed de-loading ratio is widely discussed in literature [27, 28] and it also has economic implications, where the curtailed production will lead to reduced income, however, the financial aspects are not of interest to this paper. Conversely to the partial de-loading, this method needs the frequency measurement but allows intermediate power management. This method is seen as a better option for offshore wind because of the higher and more constant wind speed profiles compared to onshore sites.

\subsection{Battery Energy Storage System (BESS)}

The BESS carries out different tasks such as the provision of frequency support, coping with the power mismatch caused by OWPCs during short-time. It also provides the balancing power to the local area for fulfilling the increment change in the imported/exported power of each AC area or OWPC according to the set-points provided by the MT-HVDC frequency support controller. The control method applied is a developed version of the control proposed in [20], implementing a rate-of-change-of-frequency (RoCoF) and droop based frequency control and an export power deviation balancing support, as shown in Figure 3. In this paper, BESS controls have the capability of providing inertia 


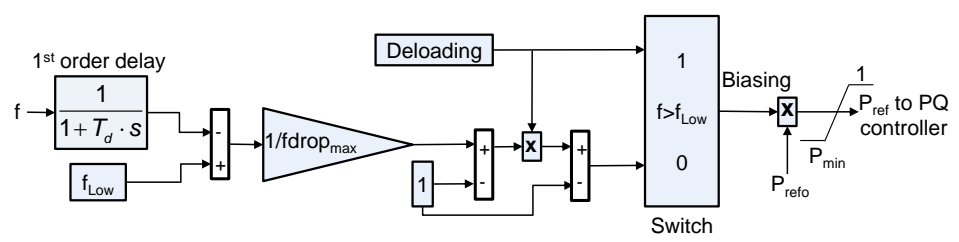

(a) Continuous droop control method diagram

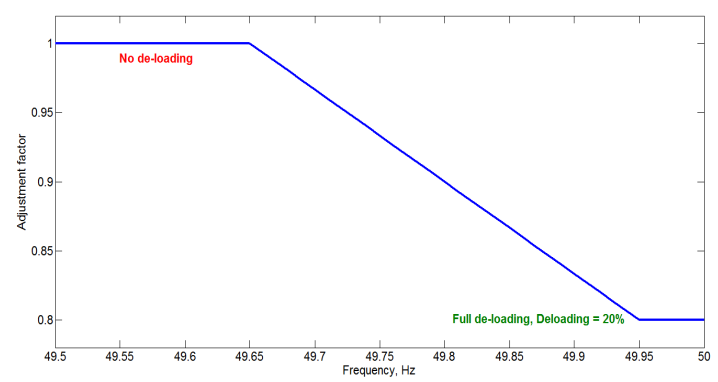

(b) De-loading factor visualization

Figure 2: Frequency control method based on droop based continuous power de-loading

response (RoCoF based support power component) and primary response (frequency drop based component) to mitigate local frequency drops in the AC area where the BESS is integrated. Moreover, the BESS can provide export support relying on the control signal received from the MT-HVDC holistic controller to export power to other AC areas via the MT-HVDC. The size of the converter station of the AC area connecting it to the MT-HVDC is considered in the control of the amount of the exported support power. The power deficits between the set-points of MT-HVDC controller and the actual outputs of both OWPCs and $\mathrm{AC}$ area are $\triangle P_{O W P C}$ and $\triangle P_{A C}$, respectively.

The local support has higher priority and it is activated when the local frequency violates a certain deadband, and there is enough energy stored (State of Charge $\left.(\mathrm{SOC})>\mathrm{SOC}_{\min }\right)$. It is worth noting that after complying with the frequency deadband, the standby mode (i.e. no charging) is activated for a certain time to avoid any successive frequency drop. The later provides the balancing power to cover any deficit from the MT-HVDC setpoint and the actual power delivered by the OWPC. This includes a narrow tolerance (acceptable error) 


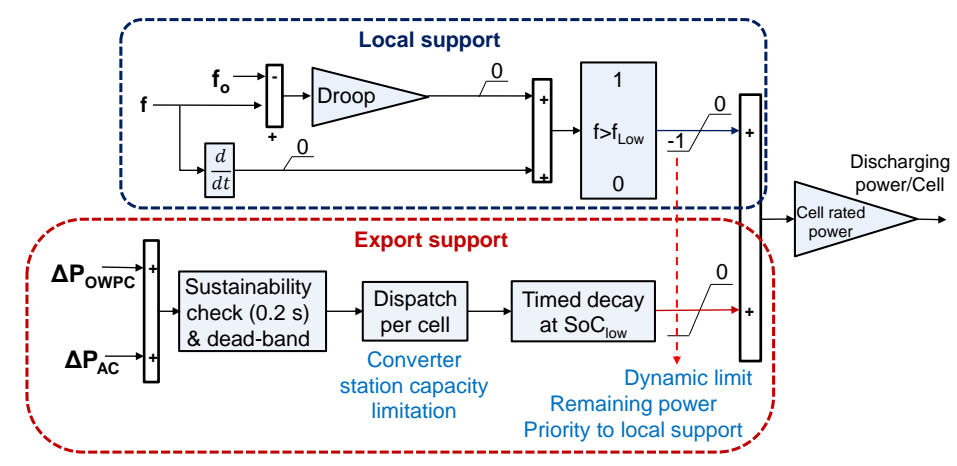

Figure 3: Schematic overview of the implemented BESS control

to avoid negative impacts on battery lifetime (cycling). Moreover, when the BESS reaches a certain threshold (close to $\mathrm{SOC}_{\min }$ ), the provided power starts to decay with a fixed rate, such that no support is provided after few seconds. This should provide enough time for the other generation assets to balance the power requirements. The RoCoF-based controllers or the PD controllers in general might raise some issues, however, in the developed BESS controller the RoCoF-based supplementary controller is complemented with a deadband and it is used to confirm that the frequency drop is growing not a normal oscillatory response due to several system dynamics. This should have a positive impact on the lifetime of the BESS, since unnecessary discharging is mitigated.

\subsection{Multi-terminal HVDC}

The applied control scheme for providing frequency support by using the MT-HVDC is presented in [24]. The control scheme used in the MT-HVDC grid is a consensus-based algorithm, which is a multi-agent control, and aims to drive different active agents, the $\mathrm{AC}$ onshore areas, in our case, to achieve a common objective, which is minimizing the frequency deviations across the connected AC areas. To achieve this, the control redistributes the power mismatches at the different AC areas connected to the MT-HVDC until reaching a consensus on the frequency stability point. A simplified block diagram of the applied control 
scheme is shown in Figure 4, where $\mathrm{n}$ and $\mathrm{m}$ are the numbers of $\mathrm{AC}$ areas and offshore WFs respectively, where $\mathrm{n}=3$, and $\mathrm{m}=2$. The main consensus controller parameters are alpha and beta with values are $20.76 \mathrm{MW}$ and 8.6 MWs respectively.

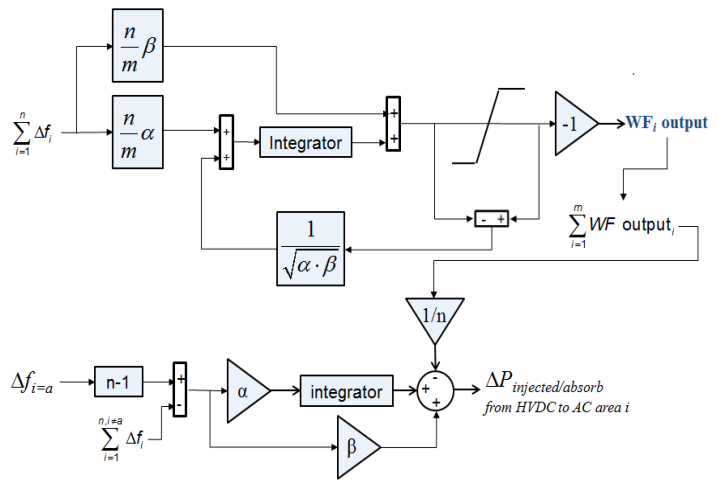

Figure 4: Simplified control scheme applied in [24]

The MT-HVDC controllers is the responsible of coordinate and distribute the support to be provided among areas and wind power to minimize the frequency deviation at any synchronous AC area. It is worth remarking that such control has information of all the converters existing at the MT-HVDC ensuring their adequate coordination.

\section{Case studies and results}

The different frequency support methods applied in the considered nonconventional technologies are tested through simulation in a well-accepted network based on the Cigré's HVDC grid benchmark [29]. This power system model is adapted for performing frequency stability studies. The network under study is illustrated in Figure 5. It includes a 5-terminal HVDC grid that connects two OWPC and three synchronous areas. Additionally, an OWF and a BESS are integrated in $\mathrm{AC}$ grids 1 and 2 respectively. The power transmitted is shared among the three interconnected areas according to the master voltage control method applied in this manuscript, which aims to achieve a balance between 

der study are listed in Table 1 [22, 24].

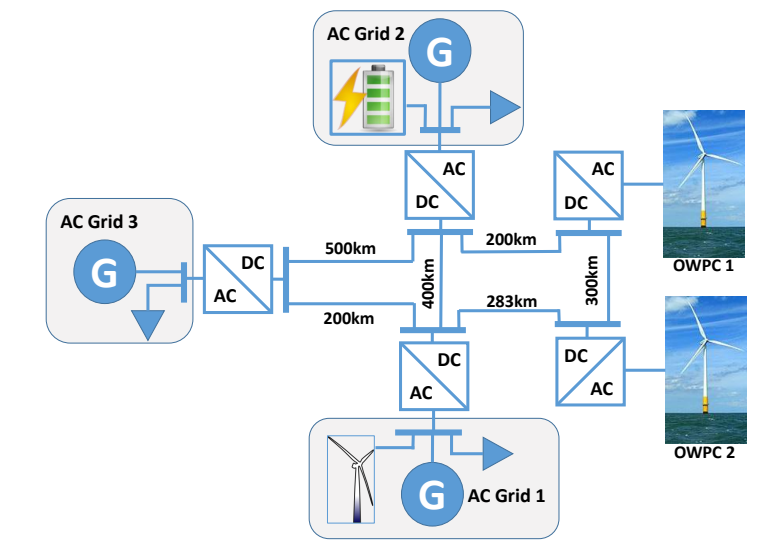

Figure 5: Simplified illustration of the MT-HVDC network under study

the imported and exported power from/to the five converter stations connected to the MT-HVDC grid. This test system could be a provisional and simplified representation of the foreseen pan-European power system where different synchronous areas in Europe e.g. UK, Norway and the Netherlands are going to be interconnected through a MT-HVDC hub.

The main specifications considered for the synchronous generation areas un-

Different types of wind turbines are used for onshore and offshore wind power plants, i.e. 2 MW Gamesa's G90 wind turbine [30, 31] and the 5 MW NREL benchmark $[32,33]$ respectively. Thus, the interactions between different wind turbine technologies are analysed. Both OWPCs and OWFs are modelled as aggregated wind turbines. The BESS installed in AC area 2 is a Li-ion Battery based station modelled as in [20]. The parameters of the non-conventional power sources are given in Table 2 , where $\mathrm{P}_{S G_{-} \text {nom }}$ refers to the nominal power of the synchronous generator and $J$ is its inertia.

The different study cases and scenarios to be considered for control performance comparison are presented. The paper analyzes five different study cases where different control strategies are activated in the same benchmark, during five different events which are illustrated in Figure 6. The events imitate real and 
Table 1: The parameters of the integrated synchronous generation

\begin{tabular}{lccc}
\hline & Area 1 & Area 2 & Area 3 \\
\hline P $_{\text {SG_nom }}(\mathrm{MW})$ & 60 & 60 & 150 \\
Loading (\%) & 4863 & 4254 & 6485 \\
$\mathrm{~J}\left(\mathrm{kgm}^{2}\right)$ & 4 & 6 & 4 \\
SG Droop (\%) & 2 & 2 & 2.5 \\
Time constant (s) & 95 & 140 & 145 \\
Load dyn. coeff. & $\mathrm{SG}+$ BESS & SG + OWF & SG \\
Freq. Support & + OWPC & + OWPC & \\
\hline
\end{tabular}

highly possible bottlenecks that may be faced by power systems, namely generation loss in both synchronous areas and offshore wind power plants due to wind speed drops. In practice, it is expected and assumed that each method has been developed independently without considering its integrative operation into the MT-HVDC where the holistic controller manages power sharing among different areas and wind farms. This could be the case when the MT-HVDC is applied in real world, where different generation assets with different control methods and parameters are integrated together. Moreover, the control of each system should mainly rely on the system where it is connected to mitigate the sophistication of the applied control method. Therefore, separate control design and parameter selection are considered and, the control parameters are not changed throughout all the cases. Due to the interactive operation of these controls, deadbands are applied. The deadbands are used as a simple coordination tool to prioritise the response of each element. Additionally, the MT-HVDC control, which is based on a consensus control provides power generation/consumption coordination among AC areas and wind farms. The consensus algorithm receives frequency variations in each area as inputs to drive their contributions. 
Table 2: Non-conventional power sources parameters

\begin{tabular}{|c|c|}
\hline \multicolumn{2}{|l|}{ BESS Stations } \\
\hline Type & Li-Ion \\
\hline Cell rated voltage $(\mathrm{V})$ & 48 \\
\hline Cell capacity (Ah) & 11.45 \\
\hline Number of cells & 7578 \\
\hline Initial SOC (\%) & 39 \\
\hline Total Rated Power (MW) & 16.4 \\
\hline Total Energy (MWh) & 5.5 \\
\hline Droop constant & $75 / f_{0}$ \\
\hline RoCoF gain & 2 \\
\hline \multicolumn{2}{|c|}{ Wind Power Generation } \\
\hline$O W P C 1(M W)$ & 30 \\
\hline 5 MW NREL WT (\#) & 6 \\
\hline$O W P C 2(M W)$ & 40 \\
\hline 5 MW NREL WT (\#) & 8 \\
\hline Onshore WF (MW) & 60 \\
\hline 2 MW G90 WT (\#) & 30 \\
\hline
\end{tabular}

\begin{tabular}{|c|c|c|c|c|c|c|}
\hline & \multicolumn{2}{|c|}{$\begin{array}{l}\text { EVENT 2: } \\
\text { Loss of } 10 \% \text { of } \\
\text { generation in } \\
\text { in } A C \text { area } 1\end{array}$} & \multirow{2}{*}{ 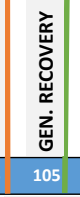 } & \multicolumn{3}{|c|}{\begin{tabular}{c|c} 
EVENT 4: & \\
Wind speed \\
drop in OWPC2 \\
from 11 to \\
$9 \mathrm{~m} / \mathrm{s}$
\end{tabular}} \\
\hline 30 & 55 & 85 & & 130 & 170 & 185 \\
\hline $\begin{array}{l}\text { EVENT 1: } \\
\text { Loss of } 10 \% \\
\text { of generation } \\
\text { in AC area } 2\end{array}$ & 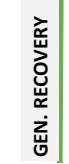 & & $\begin{array}{r}\text { EVE } \\
\text { Wind } \\
\text { reduc } \\
\text { OWPC } \\
8 \mathrm{~m} / \mathrm{s}\end{array}$ & & $\begin{array}{l}\text { EVENT 5: } \\
6 \% \text { of } \\
\text { generation } \\
\text { lost in AC } \\
\text { area 2 }\end{array}$ & \\
\hline
\end{tabular}

Figure 6: Simplified chronograph about the events considered in the study 
Table 3: Frequency deadbands considered for each technology

\begin{tabular}{|c|c|c|}
\hline \multicolumn{3}{|c|}{ Frequency drop deadbands $(\mathrm{mHz})$} \\
\hline & $B E S S$ & 20 \\
\hline & $M T-H V D C$ & 50 \\
\hline & $O W P C$ & 50 \\
\hline \multirow{3}{*}{$O W F$} & Step 1: $25 \% \Delta \mathrm{P}_{w f}$ & 30 \\
\hline & Step 2: $50 \% \Delta \mathrm{P}_{w f}$ & 45 \\
\hline & Step 3: $100 \% \Delta \mathrm{P}_{w f}$ & 60 \\
\hline
\end{tabular}

In the base case no frequency support is provided by any additional source, other than the local conventional synchronous generation. Case 1 refers to the provision of frequency support locally by some of the active power sources connected at each area as offshore wind, onshore wind and energy storage. Case 2 considers only the joint contribution of MT-HVDC and OWPCs to provide frequency support to any area that suffers a frequency drop. In Case 3, the contribution of the energy storage to cover the gaps on the power delivered/required by the MT-HVDC at both the converter station and the OWPCs is included to the Case 2. Finally, Case 4 includes all the systems (i.e. BESS, onshore and offshore wind and the MT-HVDC) providing frequency support and power balancing at the same time.

Moreover, to make the cases closer to reality, different communication delays for both local and remote measurement and control signals are considered (15 ms and $30 \mathrm{~ms}$, respectively), as well as different frequency response dead-bands depending on each technology and potential global impact, as shown in Table 3 . The dead-band values are selected based on grid code recommendations and limits [11]. 


\subsection{Case 1: Local support provided by wind power and BESS}

In this case only the provision of conventional local support is considered. The MT-HVDC frequency support controller is still deactivated. However, the set-point of active power reference at the converter station of the $\mathrm{AC}$ area facing a frequency excursion is increased to accommodate the support power incoming from the OWPC coupled to that area. The corresponding responses obtained are plotted in Figure 7. As shown in Figure 7(a), the new steady-state frequencies at each $\mathrm{AC}$ area are improved, compared to the base case, due to the additional support provided by the local non conventional power sources illustrated in Figures $7(\mathrm{~b}), 7(\mathrm{c})$ and $7(\mathrm{~d})$.

Also, it is worth noting that the frequency nadir and the RoCoF of the frequency responses in both Area 1 and 2 are better. Conversely, frequency nadir and RoCoF of the Area 3 are worsened. This is because Area 3 acts as master and it is the responsible of keeping voltage of MT-HVDC stable. Thus, it suffered a larger power unbalance due to generation reduction without being supported by any supplementary source. It must be remarked that the Base Case and the Case 1 do not operate in the same steady state frequency because of the existing power reserve from wind power used in Case 1.

As shown in Figure 7(b), the support provided by the battery is smooth allowing a steady discharge process which extends the BESS lifetime. Moreover, the delivery of energy stored from wind power (i.e. offshore and onshore) responding to the frequency decay at each local area is presented in Figures 7(c) and $7(\mathrm{~d})$. OWPCs provide some extra power, not all the reserves; whereas the OWF reaches the last step on the control leading the wind farm to its maximum value.

\subsection{Case 2: Multi-terminal and offshore wind frequency support}

Only the MT-HVDC and the OWPCs provide primary frequency support depending on the frequency dead-bands in this case. Figure 8(a) illustrates the frequency response in each $\mathrm{AC}$ area compared to the base case. As it can be seen, due to the rapid and combined response of OWPCs (shown in Figure 


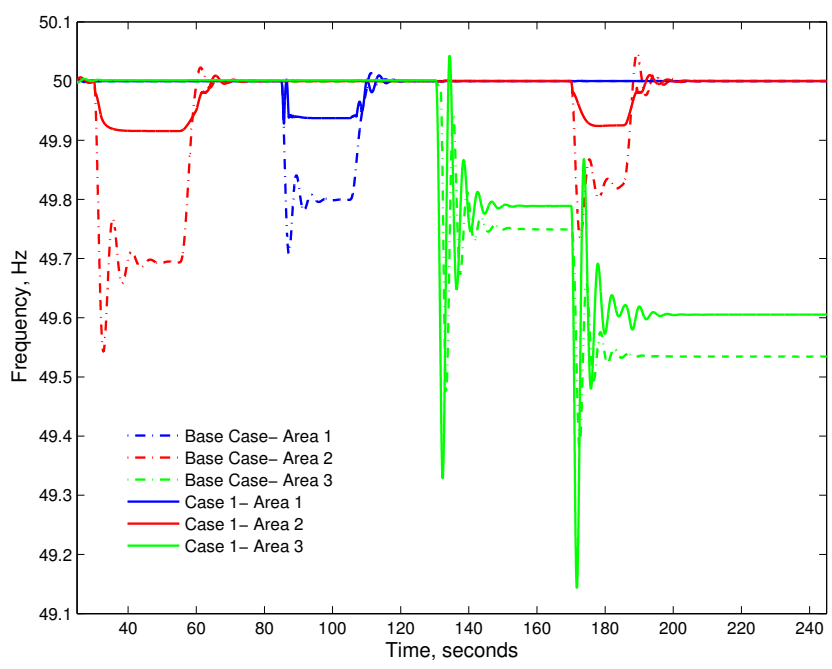

(a) Frequency responses for the different $\mathrm{AC}$ areas

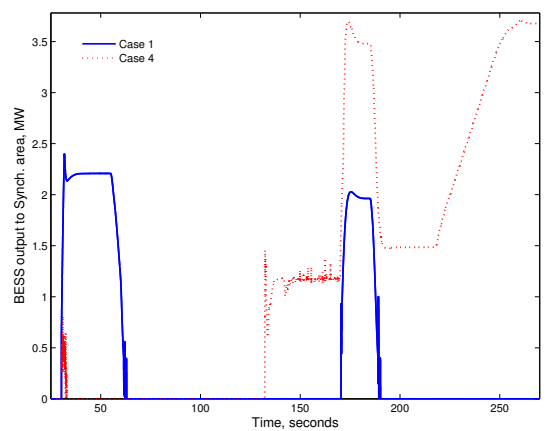

(b) Power contribution from BESS

8(b)), Areas 1 and 2 are capable to regain their nominal frequency (i.e. $50 \mathrm{~Hz}$ ) under events 1 and 2. However, during the wind speed decay in both OWFCs, the wind power plants lost their potential power reserve, and the synchronous networks start to share power requirements to achieve a common frequency. It is important to remark that the frequency control for MT-HVDC networks is capable of improving the frequency steady state value of the most affected areas, although it might have a negative impact on the $\mathrm{AC}$ areas. 


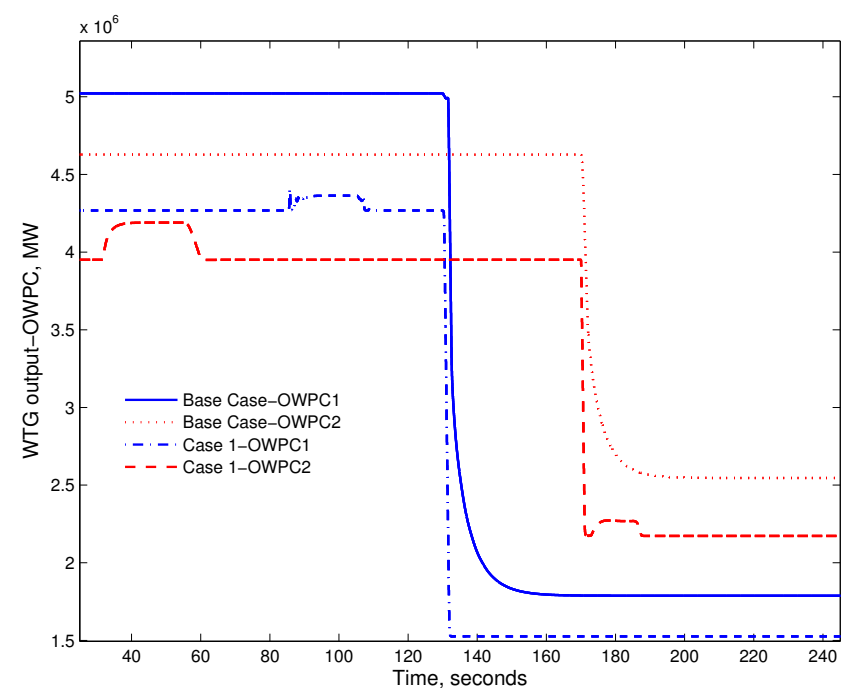

(c) Power contribution from Offshore wind farms

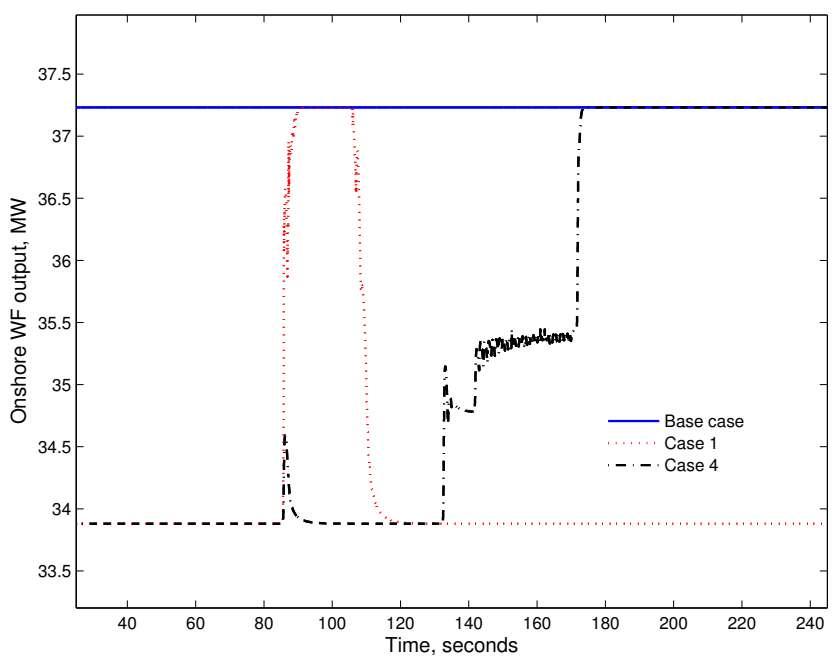

(d) Power contribution from Onshore wind farm

Figure 7: Simulation results obtained in Case 1 and compared with the base case

3.3. Case 3: $O W P C$ s and $M T-H V D C$ providing frequency support and BESS covering power sharing gap

This case considers the same control as in Case 2 with the addition of the BESS providing export power support only. As expected, the frequency re- 


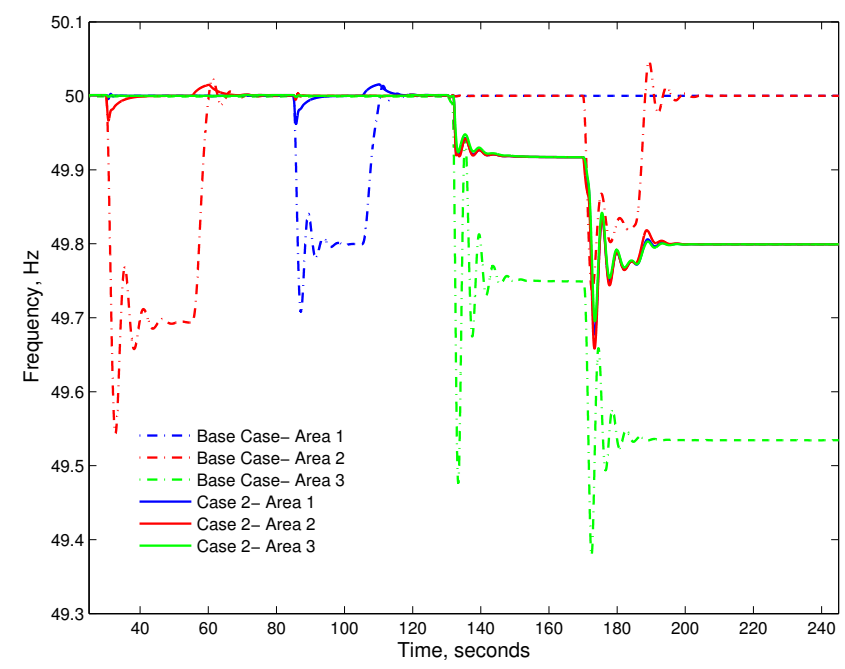

(a) Frequency responses for the different $\mathrm{AC}$ areas

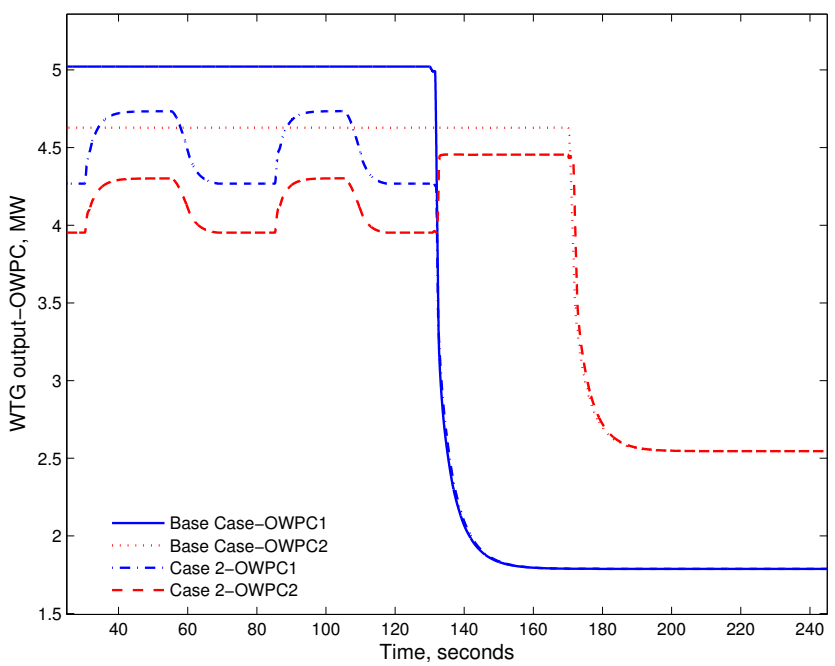

(b) Power contribution from Offshore wind farms

Figure 8: Simulation results obtained in Case 2 and compared with the base case

sponse of the different $\mathrm{AC}$ areas (see in Figure 9(a)) for events 1 and 2 are the same, since the OWPCs have enough reserve to cope with the power deviation, as illustrated in Figure 9(c). However, there is a major difference with the previous case on the frequency response for events 3,4 and 5 . In this case, 
the system showed an improved response during the wind speed drops because the MT-HVDC control shares the balancing responsibilities among the AC areas. The BESS provides additional active power as it covers the gaps between the OWPCs generation and the MT-HVDC controller set-point. Likewise, the BESS covers the gap between its local AC area nominal exported power and the actual demand from the MT-HVDC. It must be noted that this contribution is possible thanks to the up-scaled converter station on Area 2. As it can be seen in Figure 9(b), the BESS largely increases its contribution under such events for ensuring frequency stability; however, after a certain time of support the BESS reaches the threshold value close to the minimum SOC and start to reduce its contribution with a constant rate. Because of this, it can be seen in Figure 9(a), that all the synchronous areas reduce their frequency (due to power reserve sharing) until the same steady state value as previously reached in Case 2. In spite of the different applied deadbands and communication delays, no serious conflicts between the implemented support methods have been recorded.

\subsection{Case 4: All non-conventional power sources providing support}

All support methods are considered in this case, including the two supporting modes (i.e. local and export) from the BESS. Conversely to the previous case, there exist a minor improvement achieved by the system response against Events 1 and 2 as seen in Figure 10(a). As illustrated in Figure 10(b), the OWPCs behaviours are the same as the ones on Cases 2 and 3. The improvement obtained in the frequency response in events 1 and 2 is mainly related to the contribution provided by the BESS and the OWF for providing frequency support locally to their $\mathrm{AC}$ area. It is worth noting that the coordination among the different technologies for providing frequency support globally, allows to reduce the local support requirement. As it is shown in Figures 7(b) and 7(d), the response of BESS and OWF in case 4 is much lower than in case 1 for the events 1 and 2, respectively. As in the previous case, the main improvement and differences appear when the OWPCs production drops. In this case, when the offshore wind speed goes down, the BESS and the OWF start to contribute as 


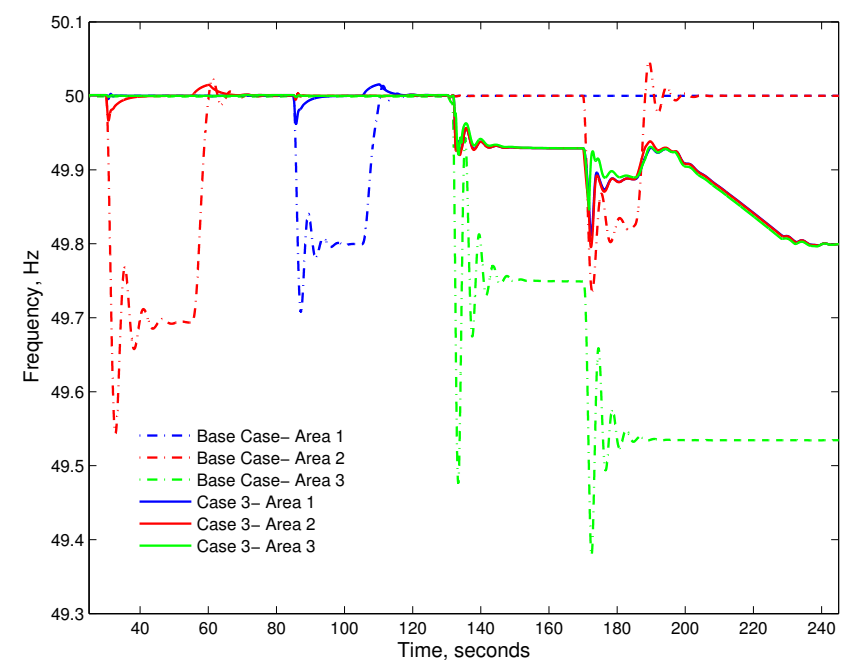

(a) Frequency responses for the different $\mathrm{AC}$ areas

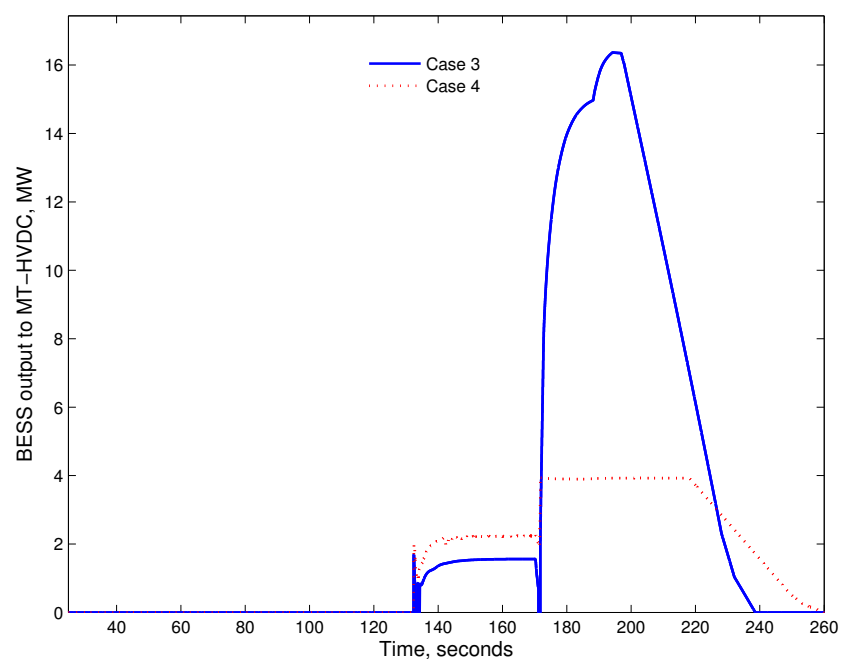

(b) MT-HVDC power balancing from BESS

presented in Figures 7(b) and 7(d). This response leads to an improved steadystate frequency of the synchronous areas by reducing the power sharing needs for balancing. Moreover, in this case the converter station of Area 2 is not upscaled, hence the BESS contribution is limited. According to that saturation, the consensus algorithm applied to the MT-HVDC do not get a common value, 


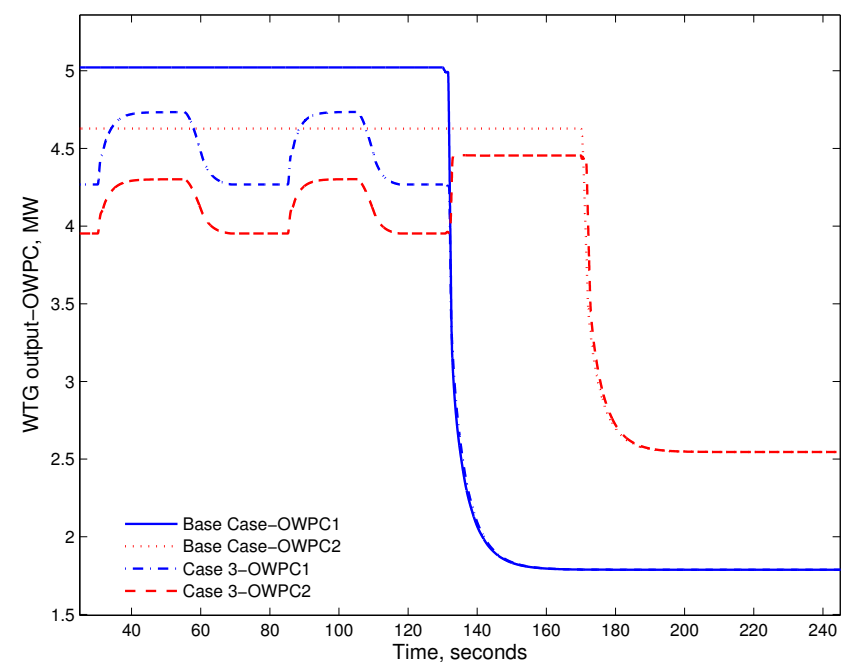

(c) Power contribution from Offshore wind farms

Figure 9: Simulation results obtained in Case 3 and compared with the base case

because the control is requiring an amount of power that the area is not capable to provide. Finally, as occurred in case 3, the BESS reduces its contribution to 0 once the fixed threshold for SOC is reached. This power removal from the BESS allows the MT-HVDC control to find a new common steady-state frequency, as seen in the right side of Figure 10(a). It is of note that the consensus has not been reached, not due to a malfunction in the holistic controller but the converter station capacity does not allow the execution of the provided set-point by the controller. Hence, the power imbalance sustains causing a steady state frequency deviation at this area, which is not similar to the other two areas.

In order to evaluate the relevance of a proper selection of the frequency deadband setting, the previous case study is reproduced, whereby the same deadband, namely $20 \mathrm{mHz}$, is applied to all non-conventional power sources providing support. As can be seen in Figures 11(a) and 11(b), an oscillatory response is obtained due to the interaction of all the systems supporting the frequency at the same time.

Analysing the full picture of the executed case studies, it is noticed that the 


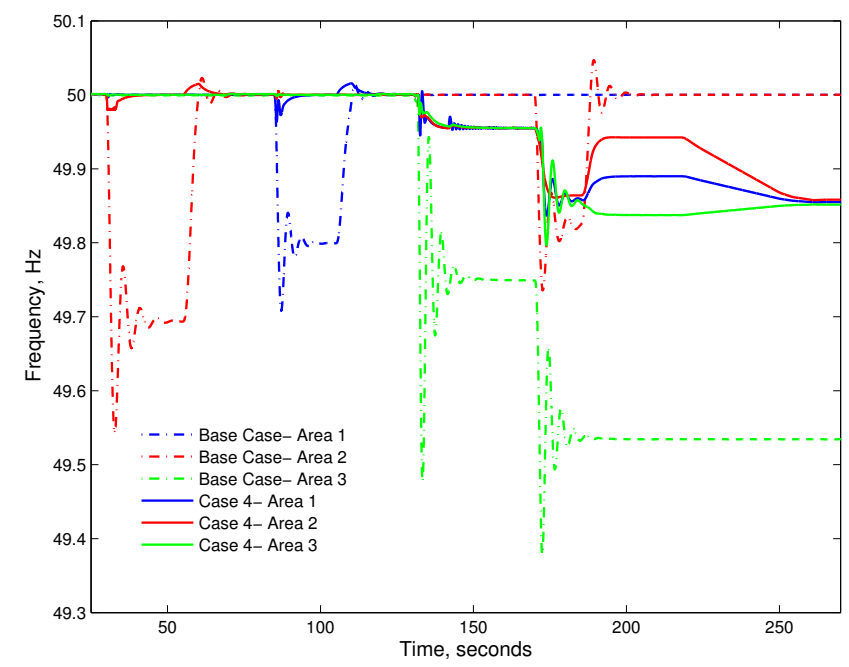

(a) Frequency responses for the different $\mathrm{AC}$ areas

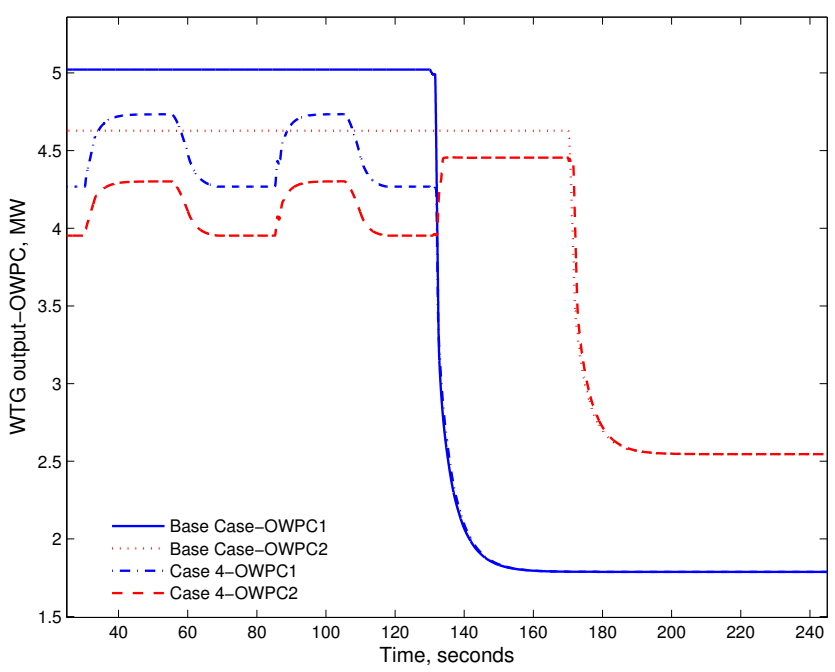

(b) Power contribution from Offshore wind farms

Figure 10: Simulation results obtained in Case 4 and compared with the base case

risk of violating grid codes is high when the non-conventional power sources are not integrated. It can be highlighted that the foreseen scenario of the interconnected AC areas with non-conventional power sources in Case 4 presented a smooth and beneficial coordination between the different control methods and 


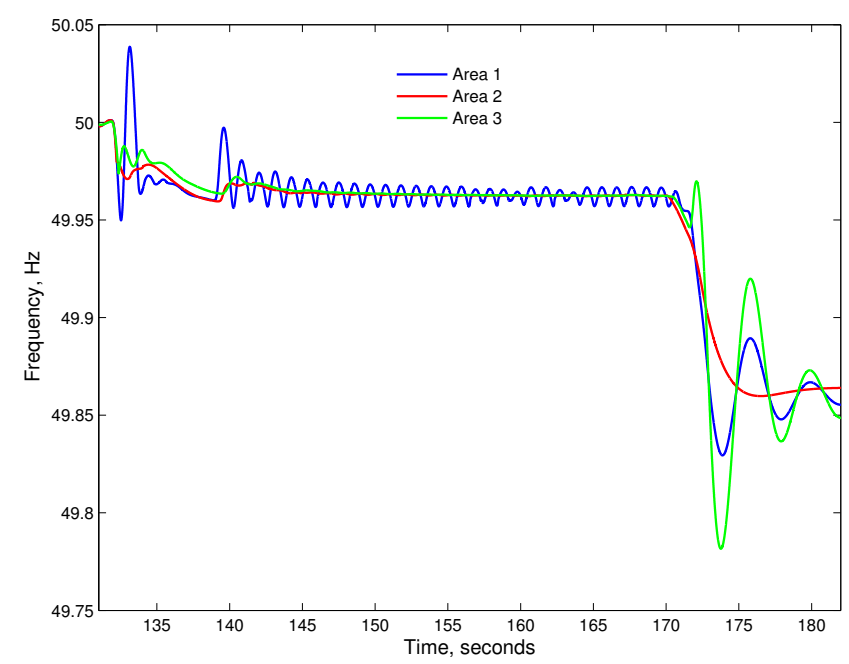

(a) Frequency responses for the different AC areas

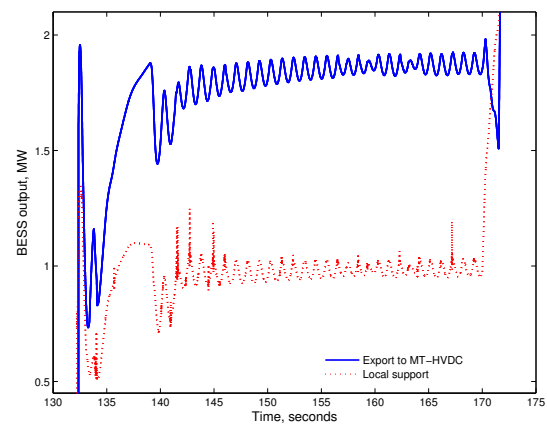

(b) Power contribution from BESS

Figure 11: Case 4 with similar frequency deadband applied for all the integrated frequency support controllers

their assigned power sources, during severe events leading to better frequency response. Thus, the adequate selection of frequency dead-bands is a key step for proper control coordination. Also, it can be extracted that the rated power of converter station of the $\mathrm{AC}$ area is of major relevance to the potential shared contribution. In particular, the insufficient size of the power converter will restrict the potential contributions from BESS and OWF as well as limit the frequency consensus regulated by the MT-HVDC controller. 


\section{Conclusion}

The foreseen interactions between different synchronous areas that are connected to a MT-HVDC grid imply many challenges to the stability of these areas and the optimum coordination between the different generation assets.

The conducted research work has evaluated and coordinated different proposed control methods for frequency stability support developed for various power-electronic based technologies such as MT-HVDC, onshore and offshore wind power as well as energy storage. The paper has focused on the potential coordination and interaction among such technologies for providing primary frequency support, taking into consideration some technical limitations and restrictions as dead-bands and communication delays.

It has been shown that system security and stability may be improved as long as the quantity of frequency support (i.e. power reserves or sharing capacity) is increased. It has been presented that the frequency support provision can be managed carefully through the coordinated MT-HVDC controller; however, some parameters must be carefully selected as dead-band, converter station sizing and energy storage to be installed. It is worth noting that, although each controller has been designed to operate alone, the conflicts between the different controllers operating together have been very limited ensuring system stability. This has been achieved through the proper selection of the frequency dead-bands providing control preference.

\section{Acknowledgment}

This work was partially supported by the EU 7th framework programs FP7ENERGY-2013 IRPWIND Project (under Grant Agreement 609795). Also, the work done by F.Bianchi and J.L. Domínguez-García is supported by the CERCA Programme from the Generalitat de Catalunya.

[1] Energy roadmap 2050, Tech. rep., European Union (2012). doi:10.2833/10759. 
[2] EWEA, Eu energy policy to 2050: Achieving 80-95\% emission reductions, Tech report., European Wind Energy Association (EWEA) (March 2011). URL http://www.ewea.org/fileadmin/files/library/publications/ reports/EWEA_EU_Energy_Policy_to_2050.pdf

[3] EWEA, The european wind initiative: Wind power research and development for the next ten years, Tech report, European Wind Energy Association (EWEA) (2010).

URL http://www.ewea.org/fileadmin/ewea_documents/documents/ publications/EWI/EWI_2010_final.pdf

[4] A. Arapogianni, J. Moccia, J. Wilkes, The European offshore wind industry - key trends and statistics 2012, Tech. rep., European Wind Energy Association (2013).

[5] I. Pineda, The European offshore wind industry - key trends and statistics 2015, Tech. rep., European Wind Energy Association (2016).

[6] R. King, Electrical Transmission System for Large Offshore Wind Farms, Ph.D. thesis, Cardiff University (2011).

[7] S. Gordon, SuperGrid to the rescue, IET Power Eng. 20 (5) (2006) 30-33.

[8] D. Van Hertem, M. Ghandhari, Multi-terminal VSC HVDC for the European supergrid: Obstacles, Renewable Sustainable Energy Rev. 14 (2010) 3156-3163.

[9] Northconnect interconnector converter station and high voltage alternating current cable route, Non-technical summary 1, NorthConnect (2015).

URL http://www.northconnect.no/files/ NorthConnect-ES-Volume-1---Non-Technical-Summary1.pdf

[10] M. Tsili, S. Papathanassiou, A review of grid code technical requirements for wind farms, IET Renewable Power Generation 3 (3) (2009) 308-332.

URL http://digital-library.theiet.org/content/journals/10. 1049/iet-rpg. 2008.0070 
[11] ENTSO-E, Network code for requirements for grid connection applicable to all generator (2013).

[12] ENTSO-E, Draft network code on high voltage direct current connection and DC-connected power park modules (Apr. 2014).

[13] Red Eléctrica de España, P.O. 12.2: Installations connected to transmission networks: minimum requirements for design, equipment, operation and commissioning (in spanish), in: Official State Gazette (BOE), no. 51, Ministry of Industry, Energy and Tourism, Spain, 2005, pp. 7416-7423.

[14] J. Morren, S. de Haan, W. Kling, J. Ferreira, Wind turbines emulating inertia and supporting primary frequency control, IEEE Trans. Power Syst. 21 (1) (2006) 433-434. doi:10.1109/tpwrs.2005.861956.

[15] A. Attya, T. Hartkopf, Control and quantification of kinetic energy released by wind farms during power system frequency drops, IET Renewable Power Generation 7 (3) (2013) 210-224.

[16] M. Fischer, S. Engelken, N. Mihov, A. Mendonca, Operational experiences with inertial response provided by type 4 wind turbines, IET Renewable Power Generation 10 (1) (2016) 17-24.

URL http://digital-library.theiet.org/content/journals/10. 1049/iet-rpg. 2015.0137

[17] G. Ramtharan, N. Jenkins, J. Ekanayake, Frequency support from doubly fed induction generator wind turbines, IET Renewable Power Generation 1 (1) (2007) 3-9.

URL http://digital-library.theiet.org/content/journals/10. 1049/iet-rpg_20060019

[18] A. Attya, T. Hartkopf, Wind turbine contribution in frequency drop mitigation-modified operation and estimating released supportive energy, IET Generation, Transmission \& Distribution 8 (5) (2014) 862-872. 
[19] N. Ullah, T. Thiringer, D. Karlsson, Temporary primary frequency control support by variable speed wind turbines - potential and applications, IEEE Trans. Power Syst. 23 (2) (2008) 601-612. doi:10.1109/TPWRS.2008.920076.

[20] A. Attya, Integrating battery banks to wind farms for frequency support provision-capacity sizing and support algorithms, AIP Journal of Renewable and Sustainable Energy 7 (5) (2015) 053125.

[21] F. Díaz-González, M. Hau, A. Sumper, O. Gomis-Bellmunt, Coordinated operation of wind turbines and flywheel storage for primary frequency control support, International Journal of Electrical Power \& Energy Systems 68 (2015) 313 - 326. doi:http://dx.doi.org/10.1016/j.ijepes.2014.12.062.

URL http://www.sciencedirect.com/science/article/pii/ S0142061514007893

[22] J. Dai, Y. Phulpin, A. Sarlette, D. Ernst, Coordinated primary frequency control among non-synchronous systems connected by a multi-terminal high-voltage direct current grid, IET Gener. Transm. Distrib. 6 (2) (2012) 99. doi:10.1049/iet-gtd.2011.0312.

[23] I. Martinez Sanz, B. Chaudhuri, G. Strbac, Inertial response from offshore wind farms connected through DC grids, IEEE Trans. Power Syst. 30 (3) (2015) 1518-1527. doi:10.1109/tpwrs.2014.2349739.

[24] F. Bianchi, J. Domínguez-García, Coordinated Frequency Control Using MT-HVDC Grids With Wind Power Plants, IEEE Transactions on Sustainable Energy 7 (1) (2016) 213-220.

[25] Z. Jiebei, J. Guerrero, W. Hung, C. Booth, G. Adam, Generic inertia emulation controller for multi-terminal voltage-source-converter high voltage direct current systems, IET Renew. Power Gener. 8 (7) (2014) 740-748. doi:10.1049/iet-rpg.2014.0109. 
[26] A. Junyent Ferre, Y. Pipelzadeh, T. Green, Blending HVDC-link energy storage and offshore wind turbine inertia for fast frequency response, IEEE Trans. Sustainable Energy 6 (3) (2014) 1059-1066. doi:10.1109/tste.2014.2360147.

[27] W. Ye, G. Delille, H. Bayem, X. Guillaud, B. Francois, High wind power penetration in isolated power systems - assessment of wind inertial and primary frequency responses, IEEE Transactions on Power Systems 28 (3) (2013) 2412-2420. doi:10.1109/TPWRS.2013.2240466.

[28] A. B. Attya, O. Anaya-Lara, W. E. Leithead, Novel metrics to quantify the impacts of frequency support provision methods by wind power, in: 2016 IEEE PES Innovative Smart Grid Technologies Conference Europe (ISGT-Europe), 2016, pp. 1-6. doi:10.1109/ISGTEurope.2016.7856322.

[29] CIGRE, Guide for the development of models for HVDC converters in a HVDC grid, Tech. rep., Working Group B4.57, Cigré (2015).

[30] GAMESA, Gamesa 2.0-2.5 mw: Technological evolution, Online Brochure (September 2015).

[31] A. B. Attya, T. Hartkopf, Evaluation of wind turbines dynamic model parameters using published manufacturer product data, in: IEEE International Energy Conference and Exhibition (ENERGYCON), 2012, pp. 184-188. doi:10.1109/EnergyCon.2012.6347748.

[32] EU FP7: AEOLUS, Simplified NREL5MW turbine for simulink, online: http://www.ict-aeolus.eu/SimWindFarm/index.html. URL http://www.ict-aeolus.eu/SimWindFarm/index.html

[33] M. Singh, E. Muljadi, J. Jonkman, V. Gevorgian, I. Girsang, J. Dhupia, Simulation for Wind Turbine Generators - With FAST and MATLABSimulink Modules, Tech. Rep. NREL/TP-5D00-59195, NREL, Golden, Colorado, USA (2014). 